\title{
Impact of COVID-19 and Partial Lockdown on Access to Care, Self-Management and Psychological Well-being among People with Diabetes: A Cross-sectional Study
}

Ester Yeoh ${ }^{1}$, Sooon Guan Tan² ${ }^{2}$ Yingshan Lee ${ }^{3}$, Ying Yee Low ${ }^{1}$, Su Chi Lim ${ }^{1}$, Tavintharan Subramaniam ${ }^{1}$, Chee Fang Sum $^{1}$, and Hwee Lin Wee ${ }^{2}$

${ }^{1}$ Admiralty Medical Centre

${ }^{2}$ National University of Singapore

${ }^{3}$ Tan Tock Seng Hospital

December 11, 2020

\begin{abstract}
Background The impact of lockdown measures can be widespread, affecting both clinical and psychosocial aspects of health. This study aims to assess changes in health services access, diabetes self-care, behavioral and psychological impact of COVID19 and partial lockdown in Singapore. Methods We conducted a cross-sectional online survey amongst people with diabetes with the Diabetes Health Profile-18 (DHP-18). Hierarchical regression analyses were performed for each DHP-18 subscale (Psychological Distress, Disinhibited Eating and Barriers to Activity) as dependent variables in separate models. Results Among 301 respondents, $45.2 \%$ were women, majority were ethnic Chinese (67.1\%), aged 40 to 49 years (24.2\%), have Type 2 diabetes $(68.4 \%)$ and on oral medications (42.2\%). During the lockdown, nearly all respondents were able to obtain their medications, supplies (94\%) and contact their doctors (97\%) when needed. Respondents reported less physical activity (38\%), checking of blood pressure (29\%) and blood glucose (22\%). Previous diagnosis of mental health conditions $(\beta=11.44, \mathrm{p}=0.017)$, diabetes-related comorbidities $(\beta=3.98, p=0.001)$ and Indian ethnicity $(\beta=7.73, p=0.018)$ were significantly associated with higher psychological distress. Comorbidities were associated with higher disinhibited eating $(\beta=2.71, p=0.007)$ while mental health condition was associated with greater barriers to activities $(\beta=9.63, p=0.033)$. Conclusion Health services access were minimally affected but COVID-19 and lockdown had mixed impact on self-care and management behaviors. Greater clinical care and attention should be provided to people with diabetes with greater number of comorbidities and previous mental health disorders during the pandemic and lockdown.
\end{abstract}

\section{Hosted file}

2. Main Text File_Impact of COVID on Diabetes DHP-18 Manuscript_11Dec2020.pdf available at https://authorea.com/users/382441/articles/498345-impact-of-covid-19-and-partiallockdown-on-access-to-care-self-management-and-psychological-well-being-among-peoplewith-diabetes-a-cross-sectional-study

\section{Hosted file}

Tables_11Dec2020.pdf available at https://authorea.com/users/382441/articles/498345-impactof-covid-19-and-partial-lockdown-on-access-to-care-self-management-and-psychologicalwell-being-among-people-with-diabetes-a-cross-sectional-study

\section{Hosted file}


3. Figures 1-2_11Dec2020.pdf available at https://authorea.com/users/382441/articles/ 498345-impact-of-covid-19-and-partial-lockdown-on-access-to-care-self-management-andpsychological-well-being-among-people-with-diabetes-a-cross-sectional-study 